Polymer Journal, Vol. 2, No. 2, pp 199-211 (1971)

\title{
Stable Conformations of 1,4-Polybutadiene Chains and Their Model Compound Molecules
}

\author{
Takehiko Shimanouchi, Yasuaki Abe, Yasuhide Alaki \\ Department of Chemistry, Faculty of Science, University of Tokyo,
} Hongo, Tokyo, Japan.

(Received October 20, 1970)

\begin{abstract}
Rotational isomerism in model compounds of cis- and trans-1,4-polybutadienes was studied. Infrared spectra in the region $600-300 \mathrm{~cm}^{-1}$ were measured for cis- and trans-2-butenes, 1-butene, 1-pentene, 1-hexene, cis- and trans-2-pentenes, cis- and trans-4-methyl-2-pentenes, cis- and trans-3-hexenes, cis-2-hexene, and 1,5-hexadiene. Normal frequencies were calculated for the low frequency vibrations of rotational isomers. From changes in the spectra in the gaseous, liquid, and solid states, it was concluded that the cis and skew conformations are stable for $\mathrm{C}-\mathrm{C}$ bond neighbouring the trans $\mathrm{C}=\mathrm{C}$ bond, and only the skew conformation is stable for the $\mathrm{C}-\mathrm{C}$ bond neighbouring the cis $\mathrm{C}=\mathrm{C}$ bond.

The stable conformations of cis- and trans-1,4-polybutadiene chains are discussed, taking into account the infrared spectra of these polymers and the stable conformations of the model compound molecules.
\end{abstract}

KEY WORDS Polybutadiene / Model Compound / Infrared Spectra / Raman Spectra/Conformation/Rotational Isomer/Normal Vibration/ Force Constant/

In a previous paper the rotational isomerism of methylbutenes and methylpentenes was studied and the stable conformations of cis- and trans1,4-polyisoprenes were discussed. ${ }^{1}$ In the present paper the same method is applied to cis- and trans-1, 4-polybutadienes and the rotational isomerism of the molecules shown in Table I is dealt with.

Table I. Model compounds studied

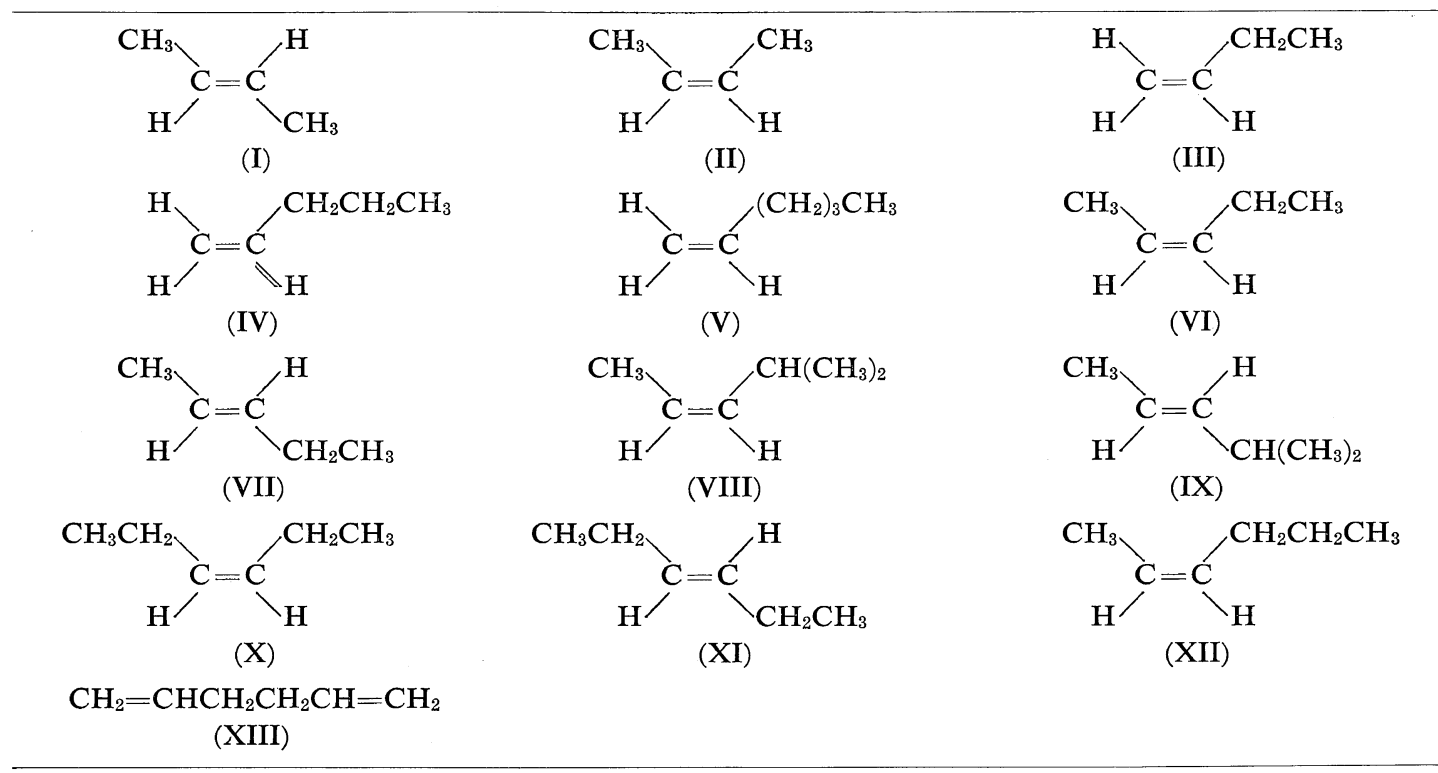


These molecules have skeletal deformation vibrations in the region $600-300 \mathrm{~cm}^{-1}$, the frequencies of which are sensitive to conformation. The spectra in this region were accordingly measured in the gaseous, liquid, and solid states and rotational isomerism was studied from the variations in these spectra.

\section{EXPERIMENTAL}

1-Butene, 1-pentene, 1-hexene, 2-pentene, 2hexene, and cis- and trans-2-butene were obtained commercially. The cis and trans compounds of 2-pentene and 2-hexene were produced by gaschromatography separation. 1,5-Hexadiene, and cis and trans compounds of 4-methyl-2-pentene and 3-hexene were provided by Tokyo Kagaku Seiki Co. and were used without further purification. Analysis by gas-chromatography for all the compounds showed that the purity of the samples was higher than 99\%. Cis- and trans1,4-polybutadienes were provided by the Bridgestone Tire Company.

The infrared spectra were recorded with an Hitachi EPI-L double-beam grating spectrometer in the region $700-250 \mathrm{~cm}^{-1}$, and with an Hitachi FIS-1 double beam grating spectrometer in the region $300-60 \mathrm{~cm}^{-1}$. Spectra in the gaseous state were measured by using a $10-\mathrm{cm}$ cell and those in the liquid state were measured with 0.025-1.0-mm cells, KBr, KRS-5 or polyethylene windows being used. To obtain solid state spectra, measurements were made at the temperature of liquid nitrogen; samples deposited on cooled KRS-5 or silicon windows were repeatedly annealed until no further spectral change was observed.

The polybutadiene films were obtained from benzene and carbon disulfide solutions.

The Raman spectra were measured at the temperature of liquid nitrogen and were obtained by using a method described previously. ${ }^{2}$

\section{CALCULATION OF NORMAL VIBRATIONS}

For the calculation of normal frequencies and their modes, a HITACHI 5020E computer in the Computer Centre of the University of Tokyo, and programs BGLZ and LSMB prepared in our laboratory were used. ${ }^{3}$ All the stretching vibra- tions were factored out by the high-frequency splitting technique.

First the calculation was made for trans-2butene, the modified UBFF being assumed and the force constants being transferred from small molecules. The result was compared with the observed infrared and Raman bands and the force constants were adjusted by the least squares method.

Secondly the normal frequencies of cis-2butene, and the cis and skew forms ${ }^{1,4,5}$ of 1 butene, cis-2-pentene, and trans-2-pentene were calculated, the force constants obtained above being used. They were used for the assignments of the observed infrared and Raman spectra. The values of the force constants associated with the skeletal deformation vibrations were adjusted. The agreement between the observed and calculated frequencies was limited, unless other force constants referred to below were taken into account. The results for the low frequency vibrations are given in the column under "Calcd I' of Table II.

Next the final least squares adjustment was made for the force constants associated with the low-frequency bands of the above seven molecules, leaving the other constants unadjusted. The cis form of cis-2-pentene was excluded, since the bands for this form were not observed. In this calculation the repulsive force constants $(R)$ for the two carbon atoms situated in the cis position, the interaction constant $(W Y)$ between the $\mathrm{CH}$ wagging and $\mathrm{C}=\mathrm{C}$ torsional modes, and the interaction constant $(W W)$ between the two neighbouring $\mathrm{CH}$ wagging modes were taken into account.

The force constants obtained are shown in Table III, where the definitions are given by

$$
\begin{aligned}
V= & \sum \frac{1}{2} K_{i}\left(\Delta r_{i}\right)^{2}+\Sigma \frac{1}{2} H_{i j} r_{i}{ }^{0} r_{j}{ }^{0}\left(\Delta \phi_{i j}\right)+\Sigma \frac{1}{2} F_{i j}\left(\Delta q_{i j}\right)^{2} \\
& +\sum \frac{1}{2} Y_{i}\left(\Delta t_{i}\right)^{2}+\sum \frac{1}{2} W_{i j k}\left(\Delta \pi_{i j k}\right)^{2} \\
& + \text { terms due to the gem internal tension }
\end{aligned}
$$

The parameters, $r, \phi, q, t$, and $\pi$ are the bond length, the bond angle, the distance between non-bonded atoms, the angle of internal rotation, ${ }^{6}$ and the out-of-plane displacement angle, ${ }^{7}$ respectively, $r^{0}$ being the equilibrium length. The values of $F^{\prime}$ appearing in the "gem internal tension is assumed to be $-0.1 F^{8}$ The structural 
Conformations of Polybutadiene Chains

Table II. Low frequency vibrations of olefin molecules $\left(\mathrm{cm}^{-1}\right)$

\begin{tabular}{|c|c|c|c|c|}
\hline Molecule & Calcd Ia & Calcd II & Obsd $^{b}$ & Assignments \\
\hline \multirow[t]{3}{*}{ trans-2-Butene } & 492 & 483 & 500 & $\mathrm{C}=\mathrm{C}-\mathrm{C}$ def. $(\mathrm{Ag})$ \\
\hline & 304 & 295 & 297 & $\mathrm{C}=\mathrm{C}-\mathrm{C}$ def. $(\mathrm{Bu})$ \\
\hline & 262 & 254 & 263 & $\mathrm{C}=\mathrm{C}$ torsion $(\mathrm{Bu})$ \\
\hline \multirow[t]{4}{*}{ cis-2-Butene } & 610 & 597 & 587 & $\mathrm{C}=\mathrm{C}-\mathrm{C}$ def. $\left(\mathrm{B}_{1}\right)$ \\
\hline & 238 & 290 & 290 & $\mathrm{C}=\mathrm{C}-\mathrm{C}$ def. $\left(\mathrm{A}_{1}\right)$ \\
\hline & 666 & 670 & 678 & $=\mathrm{CH}-$ wag. $\left(\mathrm{B}_{2}\right)$ \\
\hline & 449 & 399 & 392 & $\mathrm{C}=\mathrm{C}$ torsion $\left(\mathrm{A}_{2}\right)$ \\
\hline \multirow[t]{3}{*}{ 1-Butene (cis) } & 566 & 582 & 557 & $\mathrm{CH}_{2}$ twist. $^{\mathrm{c}}$ \\
\hline & 562 & 544 & 540 & $\mathrm{C}=\mathrm{C}-\mathrm{C}-\mathrm{C}$ def. \\
\hline & 247 & 290 & 291 & $\mathrm{C}=\mathrm{C}-\mathrm{C}-\mathrm{C}$ def. \\
\hline \multirow[t]{3}{*}{ 1-Butene (skew) } & 613 & 623 & 638 & $\mathrm{CH}_{2}$ twist. $^{c} \mathrm{CCC}$ def. \\
\hline & 441 & 431 & 433 & $\mathrm{C}=\mathrm{C}-\mathrm{C}$ def. \\
\hline & 364 & 350 & 325 & $\mathrm{CCC}$ def., =CH- wag. \\
\hline \multirow[t]{4}{*}{ cis-2-Pentene (cis) } & 640 & & & $\mathrm{C}=\mathrm{C}-\mathrm{C}$ def., $\mathrm{CH}_{2}$ rock. \\
\hline & 418 & & & $\mathrm{C}=\mathrm{C}$ torison \\
\hline & 346 & & & CCC def., $\mathrm{C}=\mathrm{C}-\mathrm{C}$ def. \\
\hline & 151 & & & $\mathrm{C}-\mathrm{C}=\mathrm{C}-\mathrm{C}$ def. \\
\hline \multirow[t]{5}{*}{ cis-2-Pentene (skew) } & 712 & 690 & 694 & $\mathrm{CH}_{2}$ twist. $^{\mathrm{c}}$ \\
\hline & 583 & 586 & 570 & $\mathrm{C}-\mathrm{C}=\mathrm{C}-$ def. \\
\hline & 485 & 456 & 455 & $\mathrm{C}=\mathrm{C}$ torsion, $\mathrm{CCC}$ def. \\
\hline & 310 & 302 & 310 & $\mathrm{CCC}$ def. $\mathrm{C}=\mathrm{C}$ torsion \\
\hline & 243 & 278 & 265 & $\mathrm{C}-\mathrm{C}=\mathrm{C}-\mathrm{C}$ def. \\
\hline \multirow[t]{2}{*}{ trans-2-Pentene (cis) } & 574 & 558 & 576 & $\mathrm{C}=\mathrm{C}-\mathrm{C}-\mathrm{C}$ def. \\
\hline & 378 & 381 & 373 & $\mathrm{C}-\mathrm{C}=\mathrm{C}$ def., $\mathrm{CCC}$ def. \\
\hline \multirow[t]{3}{*}{ trans-2-Pentene (skew) } & 497 & 485 & 488 & $\mathrm{C}-\mathrm{C}=\mathrm{C}$ def., $\mathrm{CCC}$ def. \\
\hline & 414 & 402 & 415 & $\mathrm{CCC}$ def., $\mathrm{C}=\mathrm{C}-\mathrm{C}$ def. \\
\hline & 302 & 297 & 305 & $\mathrm{C}-\mathrm{C}=\mathrm{C}-\mathrm{C}$ def. \\
\hline \multirow[t]{5}{*}{ cis-4-Methyl-2-pentene (skew-skew) } & & 590 & 586 & $\mathrm{CC}=\mathrm{CC}$ def. \\
\hline & & 479 & 500 & $\mathrm{CCC}$ twist., $\mathrm{C}=\mathrm{C}$ torsion \\
\hline & & 422 & 420 & $\mathrm{CC}$ wag., $\mathrm{CC}=\mathrm{C}$ def. \\
\hline & & 349 & 347 & CCC scis., CC wag. \\
\hline & & 272 & & $\mathrm{CCC}$ twist., $\mathrm{CH}_{3}$ torsion \\
\hline \multirow[t]{5}{*}{ cis-4-Methyl-2-pentene (cis-skew) } & & 657 & & $\mathrm{CC}=\mathrm{CC}$ def., $=\mathrm{CCC}$ def. \\
\hline & & 483 & & $\mathrm{CCC}$ twist., $\mathrm{C}=\mathrm{C}$ torsion \\
\hline & & 387 & & CCC def. \\
\hline & & 369 & & CCC scis. \\
\hline & & 290 & & $\mathrm{CCC}$ def., $\mathrm{CH}_{3}$ torsion \\
\hline \multirow[t]{6}{*}{ trans-4-Methyl-2-pentene (skew-skew) } & & 478 & 487 & $\mathrm{CC}=\mathrm{C}$ def., $\mathrm{CCC}$ scis. \\
\hline & & 450 & 460 & $\mathrm{CCC}$ wag., $\mathrm{CC}=\mathrm{C}$ def. \\
\hline & & 418 & 421 & CCC twist. \\
\hline & & 321 & 343 & CCC scis., $\mathrm{C}=\mathrm{CC}$ def. \\
\hline & & 234 & & $\mathrm{CH}_{3}$ torsion, $\mathrm{C}=\mathrm{CC}$ def. \\
\hline & & 191 & & $\mathrm{CH}_{3}$ torsion, $\mathrm{C}=\mathrm{CC}$ def. \\
\hline \multirow[t]{6}{*}{ trans-4-Methyl-2-pentene (cis-skew) } & & 557 & 568 & $\mathrm{C}=\mathrm{CCC}$ def. \\
\hline & & 423 & 438 & $\mathrm{CCC}$ def., $\mathrm{C}=\mathrm{C}$ torsion \\
\hline & & 407 & 405 & $C C C$ def. $C C=C$ def. \\
\hline & & 344 & 328 & $\mathrm{CCC}$ scis., $\mathrm{CC}=\mathrm{C}$ def. \\
\hline & & 223 & & $\mathrm{CH}_{3}$ torsion, $\mathrm{C}=\mathrm{CC}$ def. \\
\hline & & 191 & & $\mathrm{CH}_{3}$ torsion, $\mathrm{C}=\mathrm{CC}$ def. \\
\hline
\end{tabular}


Table II. (Continued)

\begin{tabular}{|c|c|c|c|c|}
\hline Molecule & Calcd I ${ }^{\mathrm{a}}$ & Calcd II & Obsd $^{b}$ & Assignments \\
\hline cis-3-Hexene & & 576 & 564 & $\mathrm{C}=\mathrm{CC}$ def., $=\mathrm{CCC}$ def. \\
\hline \multirow[t]{4}{*}{ (SS form) } & & 481 & 487 & $\mathrm{CCC}$ def., $\mathrm{C}=\mathrm{C}$ torsion \\
\hline & & 397 & 363 & CCC def. \\
\hline & & 289 & & $\mathrm{C}=\mathrm{CC}$ def., $\mathrm{CH}_{3}$ torsion \\
\hline & & 226 & & CCC def., $\mathrm{CH}$ wag. \\
\hline \multirow[t]{5}{*}{ ( $\mathrm{SS}^{\prime}$ form) } & & 579 & 575 & $\mathrm{C}=\mathrm{CC}$ def., $=\mathrm{CCC}$ def. \\
\hline & & 503 & 500 & $\mathrm{CCC}$ def., $\mathrm{C}=\mathrm{C}$ torsion \\
\hline & & 362 & 345 & CCC def. \\
\hline & & 278 & & $\mathrm{C}=\mathrm{CC}$ def., $\mathrm{CH}_{3}$ torsion \\
\hline & & 259 & & $\mathrm{CCC}$ def., $\mathrm{CH}$ wag. \\
\hline trans-3-Hexene & & 470 & 485 & $\mathrm{CCC}$ def., $\mathrm{C}=\mathrm{CC}$ def. \\
\hline (SS' form) & & 307 & 323 & $\mathrm{C}=\mathrm{CC}$ def., $\mathrm{CH}_{3}$ torsion \\
\hline \multirow[t]{3}{*}{ (SS form) } & & 421 & $(405)$ & $\mathrm{CCC}$ def., $\mathrm{C}=\mathrm{CC}$ def. \\
\hline & & 381 & (365) & $\mathrm{CCC}$ def., $\mathrm{C}=\mathrm{CC}$ def. \\
\hline & & 270 & (276) & $\mathrm{C}=\mathrm{CC}$ def., $\mathrm{CH}_{3}$ torsion \\
\hline \multirow[t]{4}{*}{ (CS form) } & & 561 & 567 & $\mathrm{C}=\mathrm{CCC}$ def \\
\hline & & 403 & (405) & CCC def. \\
\hline & & 374 & (365) & $\mathrm{C}=\mathrm{CC}$ def. \\
\hline & & 273 & (276) & $\mathrm{CH}_{3}, \mathrm{CC}$ torsion, $\mathrm{CH}$ wag. \\
\hline \multirow[t]{2}{*}{ (CC form) } & & 496 & & $\mathrm{C}=\mathrm{CCC}$ def \\
\hline & & 288 & & $\mathrm{CH}_{3}$ torsion, $\mathrm{CH}$ wag. \\
\hline
\end{tabular}

a Force constants used are $H(\mathrm{C}=\mathrm{CC})=0.32, F(\mathrm{C}=\mathrm{CC})=0.4, H(\mathrm{CCC})=0.32, F(\mathrm{CCC})=0.4, Y(\mathrm{C}=\mathrm{C})=0.64$, and $W(=\mathrm{CH})=0.35$.

b Frequencies observed in the solid state.

c Coupled strongly with $=\mathrm{CH}$ - wagging vibration.

parameters adopted are the same as those given previously. ${ }^{1}$

The values of $R$ obtained for the cis C...C repulsion are reasonable as compared with the corresponding values of $F$. As shown in Table IV, they decrease as the C...C distances increase. We ignored the $\mathrm{H} \ldots \mathrm{H}$ and $\mathrm{H} \ldots \mathrm{C}$ repulsions for the methyl or methylene groups situated in the cis position, since they are less important in the study of skeletal vibrations.

The calculated frequencies are shown in the column under "Calcd II" of Table II. The differences between the observed and calculated frequencies for these seven molecules at times exceed $10 \mathrm{~cm}^{-1}$. However, the accuracy is sufficiently high for the conformation to be discussed adequately. In Table II the frequencies calculated from these force constants are given for 4-methyl-2-pentene and 3-hexene. They were used in the conformation analysis and the assignments of the observed bands.

\section{trans-2-BUTENE}

This molecule ( $I$ in Table $I$ ) takes the $C_{2 h}$ symmetry and there is no problem in the conformation. The infrared spectra in the $\mathrm{NaCl}$ and $\mathrm{KBr}$ regions and the Raman spectra in the liquid state have already been reported..$^{9-13}$ However, we need the assignments for the skeletal deformation vibrations for the present study and the far-infrared spectra and the Raman spectra in the solid state were measured. Details are shown in Figure 1.

The Raman band at $500 \mathrm{~cm}^{-1}$ is assigned to the symmetrical $\mathrm{C}-\mathrm{C}=\mathrm{C}$ deformation vibration. The antisymmetrical $\mathrm{C}-\mathrm{C}=\mathrm{C}$ deformation and the $\mathrm{C}=\mathrm{C}$ torsional vibrations are expected to appear in the far-infrared region. The spectrum in the gaseous state has a complex band near $254 \mathrm{~cm}^{-1}$. In the solid state it becomes a doublet. The $\mathrm{C}-\mathrm{C}=\mathrm{C}$ deformation vibrations are assigned to the $297 \mathrm{~cm}^{-1}$ peak and the $\mathrm{C}=\mathrm{C}$ 
Table III. Force constants of olefins (MUBFF)

\begin{tabular}{|c|c|c|}
\hline$K(\mathrm{C}=\mathrm{C})$ & 7.42 & \\
\hline$K(=\mathrm{C}-\mathrm{C})$ & 3.24 & \\
\hline$K(-\mathrm{C}-\mathrm{C})$ & 2.40 & \\
\hline$K(=\mathrm{CH})$ & 4.39 & \\
\hline$K(-\mathrm{CH})$ & 4.23 & \\
\hline$H(\mathrm{C}=\mathrm{CC})$ & 0.287 & $(0.015)$ \\
\hline$H(=\mathrm{CCC})$ & 0.260 & $(0.028)$ \\
\hline$H(-\mathrm{CCC})$ & 0.25 & \\
\hline$H(\mathrm{C}=\mathrm{CH})$ & 0.16 & \\
\hline$H\left(\mathrm{CC}^{\prime} \mathrm{H}\right)$ & 0.23 & \\
\hline$H\left(\mathrm{C}^{\prime} \mathrm{CH}\right)$ & 0.21 & \\
\hline$H(\mathrm{CCH})$ & 0.23 & \\
\hline$H(\mathrm{HCH})$ & 0.365 & \\
\hline$H\left(\mathrm{HC}^{\prime} \mathrm{H}\right)$ & 0.37 & \\
\hline$F(\mathrm{C}=\mathrm{CC})$ & 0.40 & \\
\hline$F(=\mathrm{CCC})$ & 0.40 & \\
\hline$F(-\mathrm{CCC})$ & 0.40 & \\
\hline$F(\mathrm{C}=\mathrm{CH})$ & 0.45 & \\
\hline$F\left(\mathrm{CC}^{\prime} \mathrm{H}\right)$ & 0.51 & \\
\hline$F\left(\mathrm{C}^{\prime} \mathrm{CH}\right)$ & 0.38 & \\
\hline$F(\mathrm{CCH})$ & 0.40 & \\
\hline$F(\mathrm{HCH})$ & 0.21 & \\
\hline$F\left(\mathrm{HC}^{\prime} \mathrm{H}\right)$ & 0.21 & \\
\hline$W(=\mathrm{CH})$ & 0.359 & $(0.011)$ \\
\hline$W\left(=\mathrm{CH}_{2}\right)$ & 0.30 & \\
\hline$Y(\mathrm{C}=\mathrm{C})$ & 0.485 & $(0.043)$ \\
\hline$Y(=\mathrm{C}-\mathrm{C})$ & 0.1 & \\
\hline$Y(-\mathrm{C}-\mathrm{C})$ & 0.08 & \\
\hline$Y\left(-\mathrm{CH}_{3}\right)$ & 0.08 & \\
\hline$W W($ trans $)$ & -0.044 & $(0.017)$ \\
\hline$W W(c i s)$ & -0.005 & $(0.011)$ \\
\hline$W Y$ & 0.063 & $(0.014)$ \\
\hline$R(=\mathrm{C}-\mathrm{C}-)$ & 0.169 & \\
\hline$R(-\mathrm{C}=\mathrm{C}-)$ & 0.203 & \\
\hline
\end{tabular}

a $K, H, F$, and $R$ are given in $\mathrm{md} / \AA$ and $W, T$, $W W$, and $W Y$ in $\mathrm{md} \cdot \AA$, the values in parentheses denote statistical dispersion.

torsion to the $263 \mathrm{~cm}^{-1}$ peak, since the former is calculated to be higher in frequency than the latter. These frequencies were used for the calculation together with those assigned earlier. ${ }^{9-13}$

\section{cis-2-BUTENE}

This molecule (II in Table I) takes the $\mathrm{C}_{2 \mathrm{~V}}$ symmetry and the infrared and Raman spectra have also been reported. ${ }^{9-13}$ We measured the far-infrared and Raman spectra in the solid state. The results are shown in Figure 2.

The strong infrared band at $678 \mathrm{~cm}^{-1}$ is as-
Table IV. Repulsion constants, $F$ and $R$ in $\mathrm{md} / \AA$, and interatomic distances, $r$ in $\AA^{\text {a }}$

\begin{tabular}{l} 
r $r\left(\mathrm{C}^{*} \ldots \mathrm{C}^{*}\right)$ \\
\hline
\end{tabular}

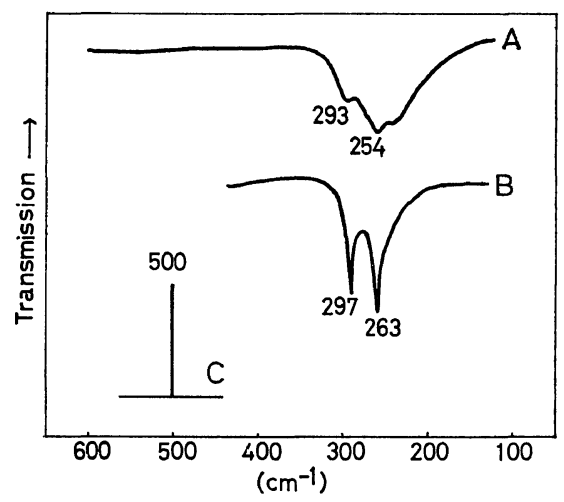

Figure 1. Infrared and Raman spectra of trans-2butene: (A) gas, infrared; (B) solid, infrared; (C) solid, Raman.

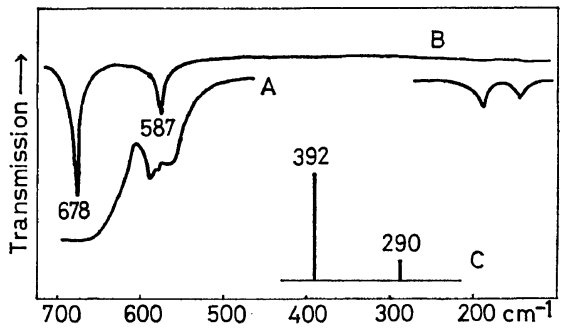

Figure 2. Infrared and Raman spectra of cis-2butene: (A) gas, infrared; (B) solid, infrared; (C) solid, Raman. 
signed to the symmetrical $\mathrm{CH}$ wagging vibration. The $587-\mathrm{cm}^{-1}$ infrared and the $290-\mathrm{cm}^{-1}$ Raman bands are assigned to the two $\mathrm{C}-\mathrm{C}=\mathrm{C}$ deformation vibrations. These assignments are supported by the frequency calculations. The remaining Raman band at $390 \mathrm{~cm}^{-1}$ is assigned to the $\mathrm{C}=\mathrm{C}$ torsion. The frequencies given in "Calcd I" of Table II are somewhat different from those observed. This fact shows that the term due to the cis C...C repulsion is needed. For "Calcd II" where the repulsion is taken into account, agreement is closer.

\section{1-BUTENE, 1-PENTENE, AND 1-HEXENE}

The microwave spectra ${ }^{14}$ showed that the 1butene molecule has two rotational isomers, cis and skew, in the gaseous state and that both isomers are almost equal in energy. The existence of isomers was also shown for the 1olefins in the liquid state from the fact that their infrared spectra have two $\mathrm{CH}_{2}$ twisting vibration bands near 550 and $640 \mathrm{~cm}^{-1}$ and that the former disappears in the solid state..$^{15}$

The infrared spectra measured are shown in Figure 3. For 1-butene and 1-pentene the lowtemperature spectra show that they are in the glassy state. We were unable to obtain the spectra in the crystalline state by means of the annealing procedure. For 1-hexene, however, repeated annealing led to crystallization and the spectrum shown in Figure 3 was obtained. The $557 \mathrm{~cm}^{-1}$ band disappeared, as reported previously. ${ }^{15}$ In addition it was observed the 312 $\mathrm{cm}^{-1}$ band also disappeared.

The fact that the $\mathrm{CH}_{2}$ twisting vibration frequencies of the two rotational isomers are different may be explained from the coupling between the twisting vibration and the skeletal deformation vibrations. When the $\mathrm{CH}_{2}=\mathrm{CH}-$ $\mathrm{CH}_{2}-\mathrm{CH}_{2}$ group takes the cis conformation, the $\mathrm{CH}_{2}$ twisting mode does not couple with the skeletal deformation modes and gives a frequency near $550 \mathrm{~cm}^{-1}$. When the group takes the skew conformation, the coupling occurs, the frequency becomes higher, and the band appears near $640 \mathrm{~cm}^{-1}$.

This explanation is supported by the normal coordinate treatment for the cis and skew forms of 1-butene as shown in Table II. All the bands

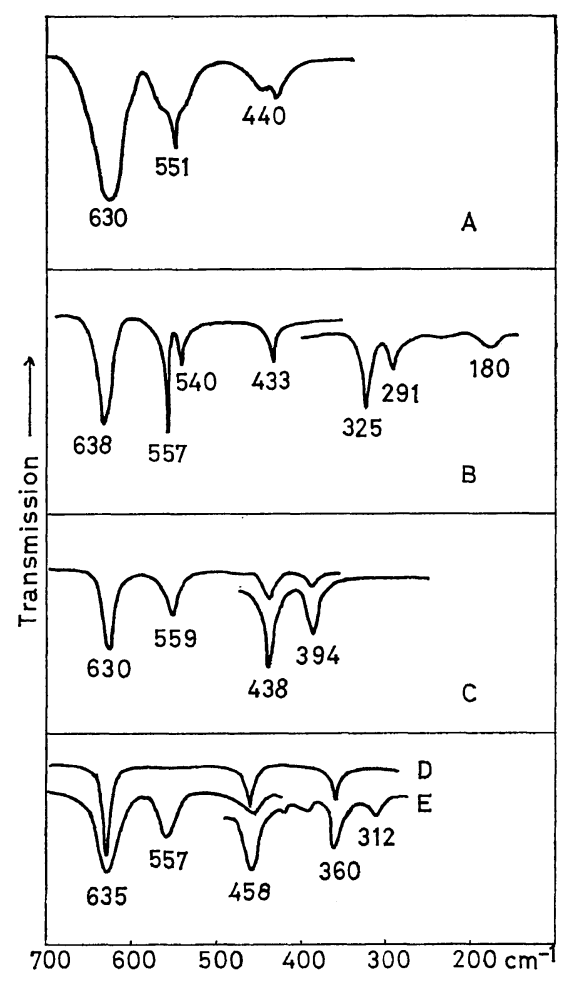

Figure 3. Infrared spectra of 1-olefins: (A) 1butene, gas; (B) 1-butene, solid; (C) 1-pentene, solid; (D) 1-hexene, crystal; (E) 1-hexene, solid.

observed in the gaseous and solid states are reasonably assigned, as given in the table. The coexistence of the cis and skew forms is shown.

For the cis form the skeletal deformation vibration frequencies for "Calcd I" are somewhat different from those observed. The situation is similar to the case of cis-2-butene and the inclusion of the cis repulsion constant improves the situation, as shown in Table II.

For 1-butene the form remaining in the crystalline state is skew. The 1-pentene and 1-hexene molecules have the $\mathrm{C}-\mathrm{C}$ axes other than that neighbouring the terminal vinyl group. Many rotational isomers are possible. In fact the two $\mathrm{CH}_{2}$ twisting vibration bands near 550 and 640 $\mathrm{cm}^{-1}$ are not single bands, but they are overlaps of two or more. In the crystalline state they become sharp, showing that only one form remains. The information available is not sufficient to enable the isomer forms to be discussed in detail. 


\section{cis-2-PENTENE}

The spectra in the liquid and solid states are given in Figure 4. The solid-state spectra show that the bands become sharp with repeated annealing; that no band disappears, and that the relative intensities of the observed bands show no appreciable change. Furthermore, the number of the observed bands is exactly as would be expected from one molecular form in this region. The existence of only one form is therefore concluded.

The frequencies of the observed bands are compared with those calculated for the cis and skew forms. As shown in Table II, the result is explained by the existence of the skew form. The agreement between the observed frequencies and "Calcd I" is close except for the lowest frequency deformation vibration. The situation is improved when the cis repulsion constant is taken into account. "Calcd II" shows the results.

This conclusion is supported by the energy of conformation. The two methyl groups are too close to each other for the cis form to be stable.

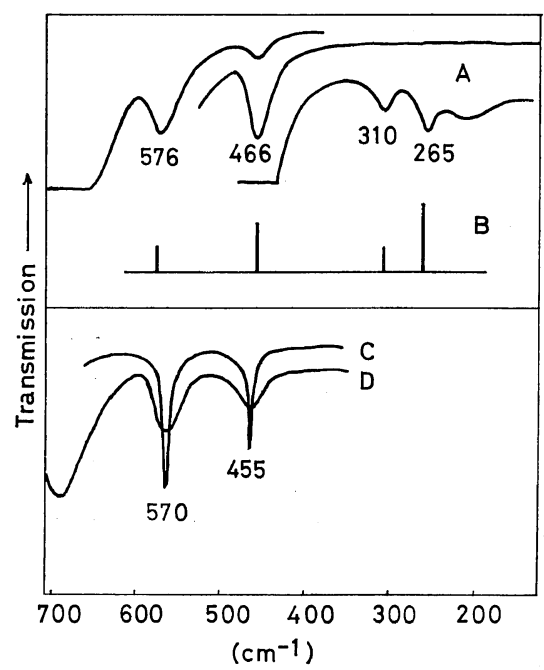

Figure 4. Infrared and Raman spectra of cis-2pentene: (A) liquid, infrared; (B) liquid, Raman; (C) crysta1, infrared; (D) solid, infrared.

\section{trans-2-PENTENE}

The spectra are shown in Figure 5. The number of bands observed in the liquid state

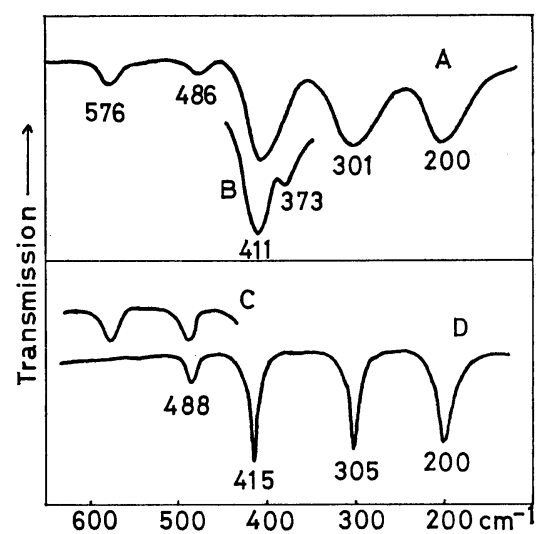

Figure 5. Infrared spectra of trans-2-pentene: (A) liquid at room temperature; (B) liquid at low temperature; (C) solid, glassy state; (D) crystalline state.

is larger than that expected for one form. The relative intensities of the bands, for example those at 576 and $486 \mathrm{~cm}^{-1}$, in the liquid state vary with changes in temperature. In the solid state two bands at 576 and $373 \mathrm{~cm}^{-1}$ disappear. This demonstrates that the two forms coexist in the liquid state.

The frequencies of the observed bands were compared with those calculated for the cis and skew forms. The results are shown in Table II. The bands remaining in the solid states are assigned to the vibrations of the skew form. Those disappearing on solidifying are assigned to the vibrations of the cis form.

The change in relative intensities of the two bands at 576 and $486 \mathrm{~cm}^{-1}$ due to the temperature variation shows that the skew form is slightly more stable than the cis form in the liquid state. The fact that the skew-form bands are stronger than the cis-form bands is ascribed to the difference in the statistical weight, the value of the skew form being twice of that of the cis form.

In contrast to the fact that the methyl group repulsion makes the cis form of the cis-2-pentene molecule unstable, the two methyl groups of the trans-2-pentene molecule are far apart even for the cis conformation. This is the reason why the cis form is as stable as the skew form for this molecule. 
cis-4-METHYL-2-PENTENE

Cis- and trans-4-methyl-2-pentene (VIII and IX in Table I) are not directly related to the structure of the polybutadiene chain. However, we include these two compounds because the method adopted in the present study can be checked from the conformation analysis of these molecules.

The methyl group repulsion discussed for the previous two compounds makes the cis-skew

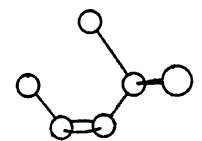

cis-skew

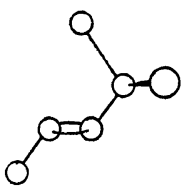

cis-skew

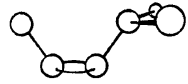

skew - skew

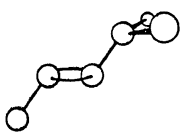

skew-skew

B
Figure 6. Rotational isomers of cis-4-methyl-2pentene (A) and trans-4-methyl-2-pentene (B).

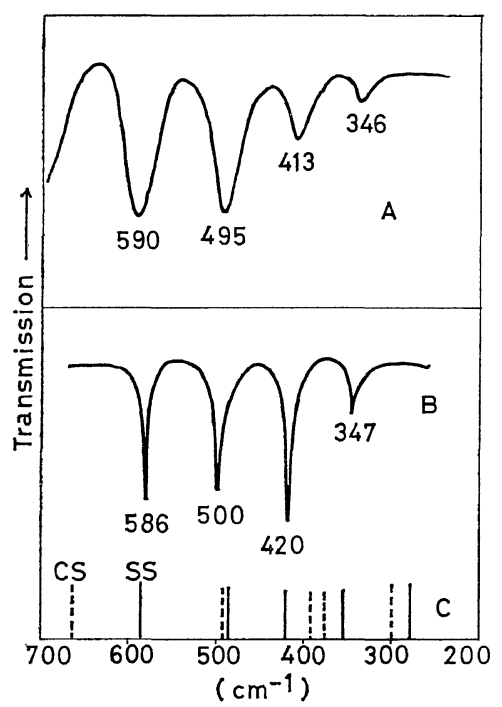

Figure 7. Infrared spectra of cis-4-methyl-2-pentene: (A) liquid; (B) crystal; (C) Calcd II. form of the cis-4-methyl-2-pentene unstable. Therefore, only the skew-skew form is expected to exist for this molecule (see Figure 6). The infrared spectra shown in Figure 7 indicate that this is the case. The "Calcd II" values for the cis-skew form (CS) and the skew-skew form (SS) are given in Figure 7. The results clearly show that only the skew-skew form exists in the liquid and solid states.

\section{trans-4-METHYL-2-PENTENE}

The preceeding discussions and the methyl group distance shown in Figure 6 suggest that the two rotational isomers, cis-skew and skewskew in Figure 6, coexist for this molecule. The infrared spectra shown in Figure 8 show that this is the case. The "Calcd II" frequencies for the cis-skew (CS) and skew-skew (SS) forms are also given in Figure 8. The bands appearing in the liquid, amorphous solid, 'and crystalline states are assigned to the vibrational modes of the skew-skew form and those appearing in the
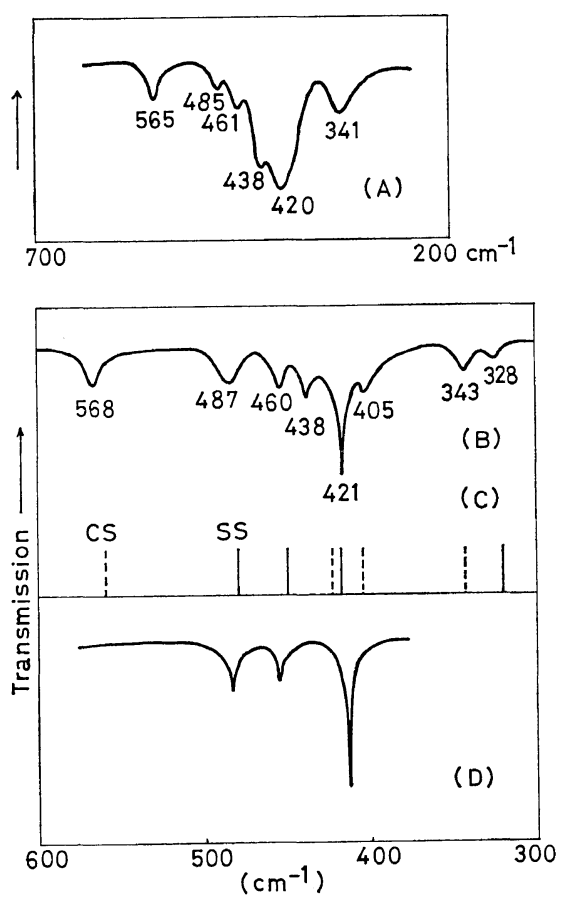

Figure 8. Infrared spectra of trans-4-methyl-2-pentene: (A) liquid; (B) amorphous solid; (C) Caled II; (D) crysta1. 
liquid and amorphous states and disappearing in the crystalline state are assigned to the modes of the cis-skew forms.

\section{cis-3-HEXENE}

Cis- and trans-3-hexenes (X and XI in Table I) are important model compounds of cis- and trans-1,4-polybutadienes. For cis-3-hexene the cis conformation of the terminal ethyl group is now rejected and the possible conformations are SCS and SCS' given in Figure 9.

The infrared spectra are shown in Figure 10. The bands near 580,490 , and $350 \mathrm{~cm}^{-1}$ are doublets in the liquid and amorphous solid states. By repeating the annealing procedure we obtain the spectrum in the crystalline state, in which the above three doublets become three sharp bands, although the last band accompanies a shoulder.

The above results show that the two isomers, SCS and SCS ${ }^{\prime}$, exist in the liquid and amorphous solid states and only one of them remains in the crystalline state.

In Figure 10 the "Calcd II" frequencies are also shown. They suggest that the form in the

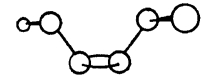

SCS

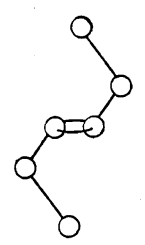

CTC

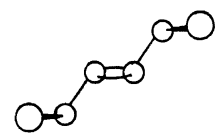

STS

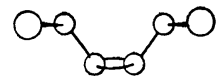

SCS

A

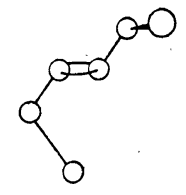

CTS

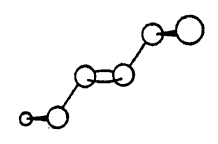

$\mathrm{STS}^{\prime}$

B

Figure 9. Rotational isomers of cis-3-hexene (A) and trans-3-hexene (B).

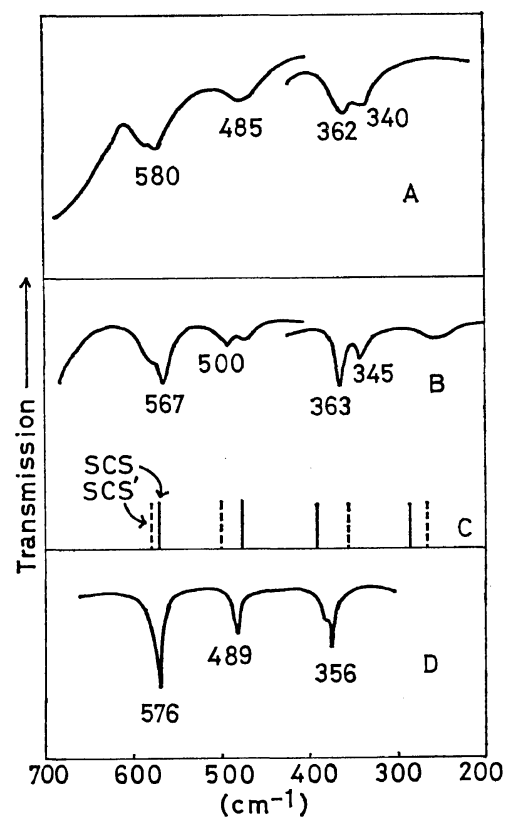

Figure 10. Infrared spectra of cis-3-hexene: (A) liquid; (B) solid; (C) Calcd II; (D) crystal.

crystalline state is probably SCS. The values of frequencies calculated however may not be sufficiently reliable to allow a valid conclusion to be drawn from this coincidence.

The changes in temperature do not alter the relative intensities of the infrared bands in the liquid state appreciably. This shows that the difference between the energies of the SCS and $\mathrm{SCS}^{\prime}$ forms is very small.

\section{trans-3-HEXENE}

The preceding discussions suggest that the trans-3-hexene molecule takes CTC, CTS, STS, and STS' $^{\prime}$ shown in Figure 9. The infrared spectra are given in Figure 11. The "Calcd II" frequencies are also given in the figure.

The properties and the estimated relative amounts of the four forms are in Table V. The CTC and STS' forms have a center of symmetry and the two skeletal deformation vibrations are infrared active. For CTS and STS the four skeletal deformation vibrations are infrared active. The estimated amount for the CTC form is smaller than those for the other three forms. 


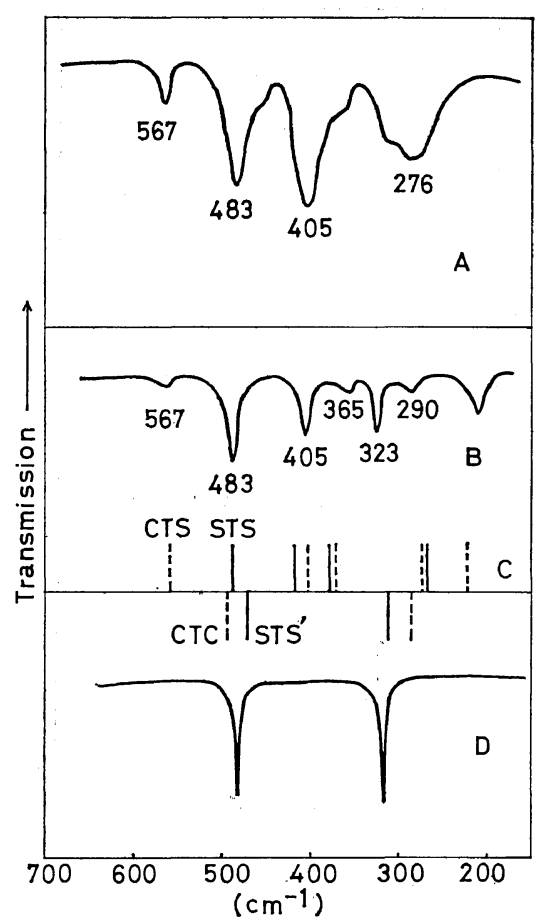

Figure 11. Infrared spectra of trans-3-hexene: (A) liquid; (B) solid; (C) Calcd II; (D) crystal.

Table V. The properties and the estimated relative amounts of the four forms of trans-3-hexene

\begin{tabular}{lcccr}
\hline & CTC & CTS & STS & STS $^{\prime}$ \\
\hline Symmetry & $\mathrm{C}_{2 \mathrm{~h}}$ & $\mathrm{C}_{1}$ & $\mathrm{C}_{2}$ & $\mathrm{C}_{\mathrm{i}}$ \\
Relative amount for $\Delta E=0^{\mathrm{a}}$ & 1 & 4 & 2 & 2 \\
$\begin{array}{l}\text { Relative amount for } \\
\quad 1 E=200 \text { cal/mola }\end{array}$ & 1 & 5.5 & 4 & 4 \\
$\begin{array}{l}\text { Number of infrared active } \\
\quad \text { skeletal deformation }\end{array}$ & 2 & 4 & 4 & 2 \\
$\quad$ vibrations & & & & \\
\hline
\end{tabular}

a The two possible values roughly estimated from the infrared spectra are used here in the discussion.

Figure 11 shows that the form remaining in the crystalline state is STS $^{\prime}$. The two bands at 483 and $323 \mathrm{~cm}^{-1}$ in the crystalline state are assigned to the two skeletal deformation vibrations of the STS' form, the frequencies of which are calculated as 470 and $307 \mathrm{~cm}^{-1}$. These two bands are strong in the liquid and amorphous solid states. This fact is consistent with the estimated relative amounts given in Table $\mathrm{V}$.
In addition to these two bands several bands appear in the liquid and amorphous solid states. They are ascribed to the bands of the CTS and STS forms. The bands due to the CTC form are not assigned. They may be too weak or overlapped by other bands.

After the present study had been completed, we were informed that Piaggio, Dellepiane, and Zerbi ${ }^{16}$ studied the infrared and Raman spectra of this compound, and compared the results with the result of the normal frequency calculation. They reached the same conclusion.

\section{cis-2-HEXENE}

This molecule (XII in Table I) has three possible conformations, $\mathrm{CST}, \mathrm{CSG}$, and $\mathrm{CSG}^{\prime}$, since the $\mathrm{CC}$ conformation is unstable and the axis of the $\mathrm{CH}-\mathrm{CH}_{2}-\mathrm{CH}_{2}-\mathrm{CH}_{3}$ group takes the trans and gauche conformations. The infrared spectra is shown in Figure 12.

The band near $460 \mathrm{~cm}^{-1}$, which is similar to the $460 \mathrm{~cm}^{-1}$ band of cis-2-pentene and is assigned to the $\mathrm{C}=\mathrm{C}$ torsion, has a doublet structure in the liquid and amorphous solid states and becomes a sharp single band in the crystalline state. This indicates the existence of rotational isomers. However, the information available is too limited for the conformations to be discussed in any detail.

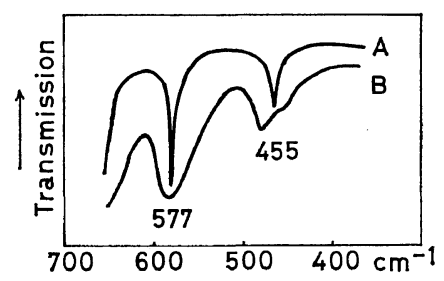

Figure 12. Infrared spectra of cis-2-hexene: (A) crystal; (B) liquid.

\section{1,5-HEXADIENE}

This molecule (XIII in Table I) has three C-C axes of internal rotation which are inserted between the two $\mathrm{C}=\mathrm{C}$ bonds. It is one of the important model compounds of 1,4-polybutadiene. The molecule has possible conformations CTC, CGC, CTS, CGS, CGS', STS, SGS, SG'S, STS', and SGS $^{\prime}$. 


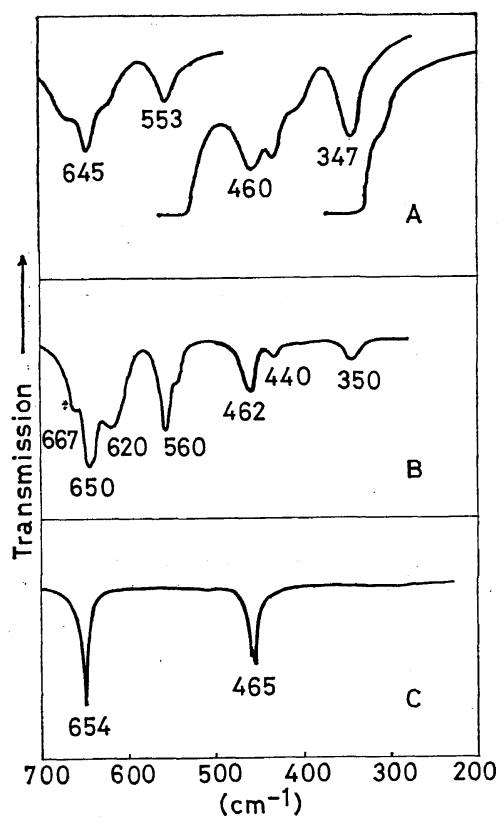

Figure 13. Infrared spectra of 1,5-hexadiene: (A) liquid; (B) glassy solid; (C) crystal.

As shown in Figure 13, the two $\mathrm{CH}_{2}$ twisting bands near 650 and $560 \mathrm{~cm}^{-1}$, which are ascribed to the skew and cis conformations of the $\mathrm{CH}_{2}=\mathrm{CH}-\mathrm{CH}_{2}-$ group, consist of two or more bands in the liquid and amorphous solid states. This may be explained by the existence of many rotational isomers. The spectrum in the crystalline state has only one sharp $\mathrm{CH}_{2}$ twisting band at $654 \mathrm{~cm}^{-1}$, showing that one form, STS, SGS

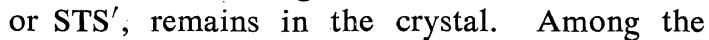
above three forms only the STS' form has a center of symmetry. The fact that only two bands appear in this region in the crystalline state also covers the possibility of STS $^{\prime}$ being that form.

\section{POSSIBLE CONFORMATIONS OF trans-1,4-POLYBUTADIENE}

The possible stable conformations can be deduced from the information on the model compounds. The 1,4-polybutadiene chain has the following four axes in one unit:

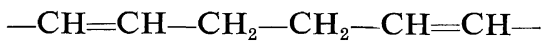

(a)

(b)

(c)

(d)

For the trans-1,4-polybutadiene the axis (a) takes, of course, trans, the axes (b) and (d) takes cis or skew, and the axis (c) takes trans or gauche. Study of the model compounds indicates that the cis form is almost as stable as the skew form in axes (b) and (d), although in the crystalline state all the molecules take the skew conformation. The energy difference between the trans and gauche forms in axis (c) is not certain. For the $n$-paraffin molecules and the polyethylene chain the gauche form is about $500 \mathrm{cal} / \mathrm{mol}$ less stable than the trans form. However, this is not always the case. For 1,4-polyisoprene the trans and gauche forms are equally stable. ${ }^{1}$ This may be the case for 1,4-polybutadiene.

The crystal structure of trans-1,4-polybutadiene has been studied by Natta and Corradini ${ }^{17}$ and Iwayanagi, et al. ${ }^{18}$ It takes (TSTS') conformations for the (a), (b), (c), and (d) axes. This is one of the stable conformations discussed above.

The infrared spectra of trans-1,4-polybutadiene are shown in Figure 14. It has two peaks at 447 and $331 \mathrm{~cm}^{-1}$ at room temperature. When the film is heated at $70-80^{\circ} \mathrm{C}$, the bands become

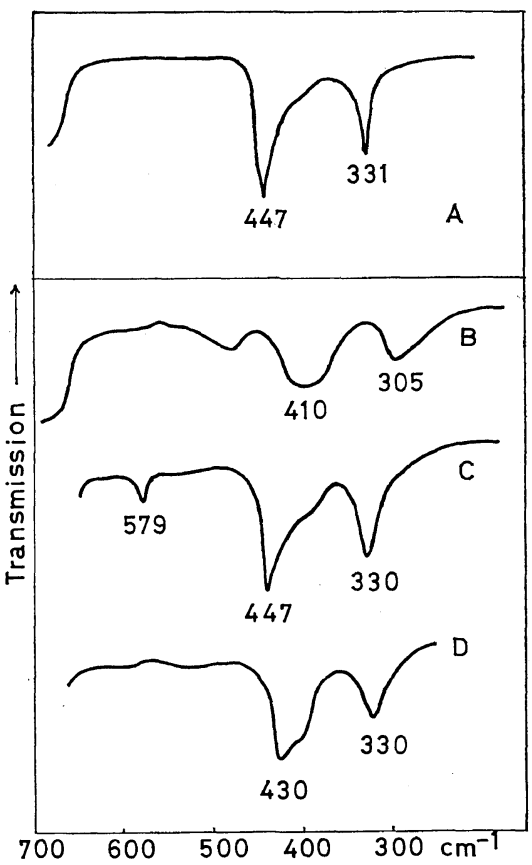

Figure 14. Infrared spectra of trans-1,4-polybutadiene: (A) film at room temperature; (B) film at $70-80^{\circ} \mathrm{C}$; (C) film cooled rapidly; (D) film annealed slowly. 
broader and are shifted to the low frequency side. When the film is cooled rapidly, a weak band appear at $579 \mathrm{~cm}^{-1}$ in addition to the above two bands. When the film is annealed and cooled slowly the $579 \mathrm{~cm}^{-1}$ band does not appear.

It is of interest to compare these spectra with the spectra of trans-3-hexene given in Figure 11. The two peaks at 447 and $331 \mathrm{~cm}^{-1}$ of the polymer correspond to those at 483 and $323 \mathrm{~cm}^{-1}$ of trans3-hexene, which belong to the STS' form. This correspondence coincides with the fact that the polymer chain takes (TSTS') conformation in the crystal.

That the two bands broaden and move to the low frequency side, when the film is heated, suggests that the polymer chain also takes the conformation (TCTS) or (TSTS), since the CTS and STS forms of trans-3-hexene have bands near 400 and $300 \mathrm{~cm}^{-1}$, as shown in Figure 11. The CTS form has a band at $567 \mathrm{~cm}^{-1}$. The fact that the polymer film which was cooled rapidly had a band at $579 \mathrm{~cm}^{-1}$ could indicate that the polymer chain partly assumes the (TCTS) conformation.

\section{POSSIBLE CONFORMATIONS OF cis-1,4-POLYBUTADIENE}

The number of possible stable conformations of the cis polymer is less than that of the trans polymer, since the axes (b) and (d) take only the skew conformation for the cis polymer chain. This is deduced from the stable conformations of cis-2-pentene and cis-2-hexene. The crystal structure of $c i s$-1,4-polybutadiene has been studied by Natta and Corradini. ${ }^{19}$ The polymer chain takes the (CSTS) conformation.

The infrared spectra of the cis polymer are shown in Figure 15. All the observed bands at room temperature are very broad and are overlapped by each other, suggesting that the cis polymer chain takes many conformations consisting of CSTS, CSTS', and CSGS. The cis polymer shows a sharp and strong band near $590 \mathrm{~cm}^{-1}$ at low temperatures as shown in Figure 15. This may correspond to the 576 or $579 \mathrm{~cm}^{-1}$ band of cis-3-hexene given in Figure 10. The band corresponding to the $489 \mathrm{~cm}^{-1}$ band of cis3-hexene is broad even at low temperature. This band is due to the torsion of the double bond

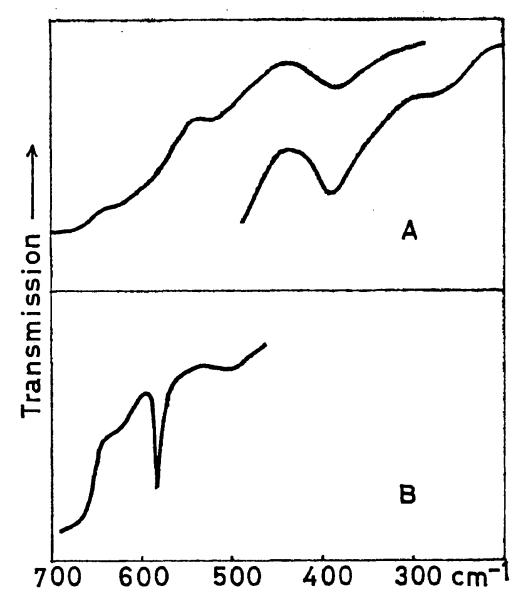

Figure 15. Infrared spectra of cis-1,4-polybutadiene: (A) film at room temperature; (B) film at low temperature.

which is inactive for cis-2-butene. The fact that this band is weak may provide information on the polymer symmetry.

\section{REFERENCES}

1. T. Shimanouchi and Y. Abe, J. Polym. Sci., Part A-2, 6, 1419 (1968).

2. S. Mizushima and Y. Morino, Proc. Ind. Acad. Sci., 8, 351 (1938).

3. T. Shimanouchi, "Computer Programs for Normal Coordinate Treatment of Polyatomic Molecules." Department of Chemistry, University of Tokyo, Tokyo, 1968.

4. T. Shimanouchi, General Discussions of Faraday Society, (in press).

5. Y. Morino and E. Hirota, Ann. Rev. Phys. Chem. 20, 139 (1969).

6. T. Miyazawa and K. Fukushima, J. Mol. Spectrosc., 15, 308 (1965).

7. T. Shimanouchi, Y. Abe, and M. Mikami, Spectrochim. Acta, 24, 1037 (1968).

8. T. Shimanouchi, "Physical Chemistry," Vol. IV, H. Eyring, D. Henderson, and W. Jost, Ed., Academic Press, New York, N. Y., 1970.

9. H. Gershinowitz and E. B. Wilson, Jr., J. Chem. Phys., 6, 247 (1938).

10. R.S. Rasmussen and R. R. Brattain, J. Chem. Phys., 15, 120 (1947).

11. J. E. Kilpatrick and K. S. Pitzer, J. Res. Nat. Bur. Stand., 38, 191 (1947).

12. L. M. Sverdlov, Dokl. Akad. Nauk SSSR., 112, 706 (1957). 


\section{Conformations of Polybutadiene Chains}

13. "Infrared Spectral Data", American Petroleum Institute Project 44, Carnegie Institute of Technology, Pittsburgh, Pennsylvania, 1952.

14. S. Kondo, E. Hirota, and Y. Morino, J. Mol. Spectrosc., 28, 471 (1968).

15. L. A. Harrah and D. W. Mayo, J. Chem. Phys., 33, 298 (1960).

16. P. Piaggio, G. Dellepiane, and G. Zerbi, to be published.

17. G. Natta and P. Corradini, Nuovo Cimento Suppl., 15, 9 (1960).

18. S. Iwayanagi, I. Sakurai, T. Sakurai, and T. Seto, J. Macromol. Sci., B2, 163 (1968).

19. G. Natta and P. Corradini, Nuovo Cimento Suppl., 15, 111 (1960). 